\title{
Research on the Optimization of Scientific and Technological Financial Service Platform in Big Data Environment
}

\author{
Ying Wang a \\ Scientific Research and Production Base Management Service Center of Henan Province, \\ Zhengzhou 450008, China \\ a1349647199@qq.com
}

Keywords: Science and Technological Financial, Service Platform, Big data.

\begin{abstract}
At present, China's scientific and technological financial service platform has developed rapidly, but it is still far from meeting the needs of all aspects. This paper first discusses the current situation of the technology financial service platform, analyzes the impact of the big data technology financial service platform, and finally, combined with the practice, puts forward several measures for the optimization of the science and technology financial platform.
\end{abstract}

\section{Current Situation of Science and Technology Financial Service Platform}

At present, with the development of science and technology finance, various types of scientific and technological financial service platforms have been launched. Such as Jiangsu, Chongqing, Sichuan, Beijing, Guangdong, Henan and other provinces (cities, districts) have established various types of platforms. To provide scientific and financial services for enterprises, financing institutions and banks, there are generally two channels for government funds to establish funds or parent funds to guide private capital into technology companies and diversified technology companies. These include government support, technology loans, and technology guarantees. Equity investment, multi-level capital markets, technology insurance and technology leasing. The construction and operation of these platforms have played a very good role in promoting the development of science and technology, the transformation of achievements, and the development of high-tech industries.

However, in the background of the rapid development of science and technology finance, it should be seen that the development speed of science and technology finance lags far behind the needs of enterprises and society. Due to its own characteristics, scientific and technological achievements and technical assets cannot be accurately measured scientifically, and long-term benefits cannot be accurately estimated. The trading of scientific and technological achievements is not the same as the general products, and there are often cases in which transactions are difficult. Because of various reasons, the operational science and technology financial service platform has its limitations. Mainly in the following several aspects: First, in the entire technology and financial cycle, for early enterprise declarations, financial institutions, more attention to docking, but for the entire process, the coverage is too narrow, follow-up services are not comprehensive, not systematic; Second, the amount of data information is too small, and the existing data utilization rate is too low. It is limited to the registration information of enterprises and related supply and demand data. The function is mainly the release and search of information, lack of enterprise background, industry development, related policies, and other data, and cannot be applied to enterprises. The financing needs are evaluated in a comprehensive and reliable manner. Third, the products provided by the current technology finance platform are single, and the coverage of financial products is very small. The products do not consider the structural features of the development of technology-based companies and small and micro enterprises and the capital requirements in different stages; Fourth, the range of potential investment target platform is too narrow. Most platforms are only targeted at certain types of companies or certain types of enterprises. The scale and industry of companies have greater limitations. As the current mechanism supporting the development of SMEs in China is still far from perfect, the financing channels for SMEs are still banks in the traditional sense. However, SMEs 
often lack the credit credentials needed for credit, and the cost of bank monitoring is high, resulting in the existing platform, financing of small and medium-sized enterprises is very difficult; Fifth, although the scientific and technological financial platform plays a great role in promoting the exchange of information between enterprises and financial institutions, but the current cost of capital supply and demand in the financing process is still relatively high. Sixth, the operating mode of the existing financing platform has not been commercialized, and a considerable part of the operating costs has come from financial funds of all levels of government.

\section{The Impact of Big Data Environment on Science and Technology and Financial Platform}

The scientific and technological financial service platform has broken through the geographical restrictions in the traditional financial transaction model, making it possible for both sides of the capital supply and demand to find suitable resources and objects through the platform, which provides an effective way to solve the matching of capital supply and demand. In recent years, the rapid development of big data technology has also provided more powerful technical support for the development of science and technology finance. "Big data" refers to a large data set that has been collected from many sources in multiple forms. Its characteristic lies in the excavation of massive amounts of data. First, big data technology can greatly expand the financing channels. Through the analysis and in-depth excavation of private capital data, private capital financing databases can be established to provide more abundant funding sources and more and better distribution channels for science and technology finance; Second, the application of big data technology will greatly reduce the probability of information distortion and improve the reliability of information. The data sources for big data analysis are not limited to the limited information exchanged between the fund supply and demand sides on the S\&T financial platform, but may be social networking, taxation and social security departments, e-commerce websites, visiting records, and other sources. Information is also explicit and implicit. Manifestations. The mining and analysis of these data will obviously reduce the possibility of information distortion. Third, the introduction of big data technology will greatly reduce financing costs. Traditional financial institutions need to spend a lot of manpower and material resources and time costs in the process of reviewing companies with financing needs. Under the support of big data technology, through the interaction of information on the supply and demand sides of funds and related information mining, through data modeling, Analysis and calculation can obtain more reliable enterprise evaluation results and financing needs information, thereby effectively reducing financing costs and financing process time, and reducing the burden on both sides of funds supply and demand; Finally, the intervention of big data technology will greatly promote the credit system. perfect. The big data environment can establish data collection, management, and analysis models from raw materials, production to sale process, and monitor this whole process before lending, improve credit data in a digital way, and establish credit in a reliable way.

\section{Function Optimization of Science and Technology Financial Service Platform in Big Data Environment}

Big data technology provides us with technical support and analysis methods for the optimization of the financial services platform. Based on the data analysis, we should optimize and improve the financial service platform of science and technology in the following aspects, combining the present situation and the actual situation.

\subsection{Enhancing Platform Openness, Promoting Data Sharing and Data Flow}

One of the characteristics of big data is massive data, which includes two aspects of data sources and categories. Its core value lies in the storage and analysis of massive data, which requires the establishment of an open operating platform. However, the openness of existing technology and financial service platforms is generally poor. Nearly 100 related platforms that have been established are basically independent operations. Between the platforms, between the platform and the outside, 
architecture design, platform of data information basically is in a closed state. Obviously, this is not conducive to the use of data resources and improve the use of technology financial services platform. Therefore, improving the openness and ease of use of the platform and strengthening the sharing and exchange of data with other platforms and external data are the primary tasks for improving the matching ratio between the supply and demand of funds.

\subsection{Expanding Financing Products to Realize Fine Division and Accurate Distribution of Financing Products}

One of the important applications results of big data is the accurate delivery of products. Through the data collection and analysis of different stages of the company's type, industry, and life cycle, fully consider the different financing needs of various stages of the enterprise life cycle, the sources of funds for the platform, and various comprehensive information of the investment institutions, etc., to precisely match the multi dimension and implementation of the fine division of financing products. Through the excavation and analysis of a company's product conditions, capital flows, costs and other related information, it initially determines the range of financing products that the company needs, and recommends and matches the company and financing institutions, so as to reduce costs and improving matching. rate.

\subsection{Provide Full Life Cycle and Full-process Service for Technology Finance in Big Data Environment}

Big data technology provides guarantees for the whole process of science and technology finance throughout the life cycle, thus strengthening the coordination of science and technology financial service platform in the process of corporate financing and realizing from enterprise application to both fund supply and demand contracting, contract evaluation and tracking the whole process of service. At the enterprise application stage, the company completes basic information filling and registration. The authenticity, accuracy and rationality of the information at this stage can be verified and verified through the mining and analysis of related external data. In the stage of information search and project docking, the preliminary recommendation results are given by data mining and analysis of products and financing conditions provided by platform registration users and financiers. The sources of data in this process should include platform-owned information and information mined from other sources. In the implementation phase of the project, by tracking and analyzing of various types of data of the enterprise, the basic operation of the enterprise can be obtained at any time and the use of financing can be effectively supervised. At the end of the project, the project implementation status and other data analysis can be combined to evaluate the use and income of funds, the integrity of both sides, and the issues of the project implementation process.

\subsection{Establishing Evaluation Models Based on Big Data}

The ideal state of the science and technology financial service platform is to be able to automatically evaluate the integrity and operations of companies and financing institutions, so as to provide a preliminary screening scope for financing institutions and enterprises. Obviously, it is impossible to accomplish this task simply relying on the data information within the platform. At the same time, the evaluation is based on data and evaluation indicators. It is meaningful to establish evaluation indicators only on the basis of data. Therefore, it is necessary to apply big data technology to conduct excavation and screening and analysis in massive data, so as to achieve precise matching demands and establish and improve various evaluation systems.

\section{Summary}

The technological financial service platform has been developed rapidly, but it is far from meeting the needs of all aspects. The application of big data technology to optimize the platform, enhance the openness of the platform, achieve accurate delivery of financing products, and provide full-process services for the full life cycle of science and technology finance, to provide real and reasonable and comprehensive information for all parties involved in business and investment, thereby establishing effective docking channel, improve the success rate of docking is the development direction of the technology and financial service platform. 


\section{References}

[1]. Xiangting Ji. Research on Personal Finance Mode under Internet Finance[J]. Chinese Commercial Theory: Henan University, 2016,10(21):79-80.

[2]. Tian Chuan. Analysis of Funds Management Mode under Internet Finance Model[J]. Finance Theory and Teaching, 2015(02):26-29.

[3]. Lu Xin, Wang Liuxi, Yang Yi. Research on Internet Finance and Financing Cost of Small and Micro Enterprises[J]. Management Modernization, 2014(05).

[4]. Wang Xin. Internet finance to help solve the financing dilemma of small and micro enterprises based on "long tail theory" analysis [J]. Credit, 2014 (03).

[5]. Shusong Bai. Big data solvability bottleneck for small and micro enterprises [J]. China Economic Report, 2013(06).

[6]. Xie Ping, Zou Chuanwei. Research on Internet Financial Model [J]. Financial Research, 2012(12).

[7]. Wenhui Zhang. The Impact of Internet Finance on Accounting Development and Measures[J]. Chinese and Foreign Entrepreneurs, 2017, (18): 74-75 